\title{
PENERAPAN ESP DI PERGURUAN TINGGI UMUM (NON ENGLISH MAJORS) MELALUI PENDEKATAN CONTENT-BASED INSTRUCTION-CBT
}

\section{(ESP APPLICATION AT NONENGLISH MAJORS OF HIGHER EDUCATION THROUGH CBT APPROACH)}

\author{
Muhamad Nur \\ Sekolah Tinggi Managemen Informatika dan Komputer (STMIK) Bumigora Mataram \\ Jl. Ismail Marzuki_Mataram-NTB \\ Pos-el: insabil@gmail.com
}

Diterima: 9 April 2018; Direvisi: 9 Mei 2018; Disetujui: 21 Mei 2018

\begin{abstract}
Abstrak
Mata kuliah bahaa Inggris di perguruan tinggi umum (nonEnglish majors) di Indonesia pada umumnya adalah sebagai bagian dari mata kuliah pengembangan kepribadian. (MPK). Kelompok mata kuliah tersebut termasuk dalam kurikulum institusional yang isinya disesuaikan menurut ciri khas perguruan tinggi (PT) yang bersangkutan dengan mengacu kepada Keputusan Menteri Pendidikan Nasional (Kemendiknas) Nomor: 232/U/2000. Karena kurikulumnya disusun secara institusional, maka kurikulum dan silabus mata kuliah tersebut ditengarai tidak selalu mencerminkan ciri khas PT bersangkutan. Ciri khas dalam konteks pembelajaran bahasa Inggris ini hendaknya menerapkan bahasa Inggris untuk tujuan khusus (English for Specific Purposes yang disingkat ESP) dengan pendekatan CBT yang mengintegrasikan bahasa Inggris untuk akademik (English for Academic Purposes yang disingkat EAP) dan bahasa Inggris untuk pekerjaan atau profesi (English for Occupation yang disingkat EOP). Metode penelitian ini adalah bersifat deskriptif kualitatif terhadap data yang diperoleh dengan mengidentifikasi dan mengobservasi kurikulum dan silabus mata kuliah bahasa Inggris yang telah diterapkan sejak tahun 2007 pada delapan PT yang diperoleh secara acakbaik negeri maupun swasta serta jenis PT. Dari sejumlah silabus tersebut, dua diantaranya dilakukan survei langsung karena lokasinya terletak di daerah yang sama dengan PT penulis yang dikatagorikan sebagai data primer. Sedangkan lainnya diperoleh melalui penelusuran internet (online) yang dikatagorikan sebagai data sekunder. Berdasarkan data tersebut menunjukkan bahwa materi pembelajaran termasuk dalam tiga katagori, yakni; (1) English for General Purposes (data: PT-1, PT-2, dan PT-7), (2) English Grammar (data: PT-3, PT-4, dan PT-6), (3) ESP dan English for General (data PT-5, dan PT-8). Dengan demikian, tidak terdapat program studi dari sejumlah PT tersebut yang menerapkan pembelajaran ESP dengan pendekatan CBT pada mata kuliah bahasa Inggris yang mencerminkan ciri khas bidang keilmuannya pada semua PT tersebut.
\end{abstract}

Kata kunci: ESP, perguruan tinggi umum, $C B I$

\begin{abstract}
English course at nonEnglish majorsof Higher Education (HE) settings in Indonesia is part of a personal development courses 'Matakuliah Pengembangan Kepribadian-MPK'. The course is including in the Institutional Curriculum, which its content is based on the related HE typical referring to the National Education Ministry Decree 'Kepmendiknas' Number 232/U/2000. Since the institutional curriculum is composed institutionally, so its content was assumed not always represent the related HE typical. The typical of English learning in this context is should applied the English for Specific Purposes (ESP) with CBT approach that integrate the English course for Academic purposes (EAP) related to the field of study and the English for Occupation Purposes (EOP) related to the job or profession in the future. The research method was a qualitatif descriptif which was conducted through identification and observation of the curriculum and
\end{abstract}


syllaby of English course that had been applied since 2007.at eight states and private, and types of the HE that taken randomly. Referring to the collected syllabus, two were taken throughdirectly survey because the location was the same region with the author which categorized as the primer data, and the others cattegorized as the seconder data which were taken through internet access. Based on the data, it is shown that the learning materials of the HE were included into three categories; (1) English for General Purposes (data HE-1, HE-2, andHE-7), (2) English Grammar (data HE-3, HE-4, andHE-6), (3) ESP and English for General (dat HE-5, andHE-8). Therefore, none of the study program was applied the ESP with CBT approah for the English course that representing the field of study at all those of HE.

Keywords: ESP, nonenglish majors, $C B I$ 


\section{Pendahuluan}

Pembelajaran bahasa Inggris sebagai mata kuliah di Perguruan Tinggi (PT) umum (non-English Majors) di Indonesia termasuk dalam kelompok Matakuliah Pengembangan Kepribadian (MPK). Menurut kepmendiknas Nomor: 232/U/2000, mata kuliah tersebut termasuk kurikulum institusional yang isi dan orientasinya ditentukan oleh masing-masing institusi menurut ciri khas perguruan tinggi yang bersangkutan. Ciri khas PT yang berkenaan dengan materi/isi mata kuliah dalam konteks lingkup akademik semestinya menerapkan pembelajaran bahasa Inggris tujuan khusus (English for Specific Purposes, yang selanjutnya disingkat ESP) sesuai dengan bidang atau program studi. Pada saat yang bersamaan, bahasa Inggris sangat dinamis seiring dengan perkembangan ilmu pengetahuan, teknologi, dan seni (Ipteks) secara global. Kedinamisan bahasa Inggris dalam konteks perguruan tinggi (PT) setidaknya dapat diukur dari dua hal, yakni pembelajaran bahasa Inggris berbasis disiplin keilmuan atau program studi yang dikenal dengan English for Academic Purposes (EAP) dan pembelajaran bahasa Inggris yang berorientasi pada kepentingan profesi atau pekerjaan yang dikenal dengan English for Occupation (EOP). Keduanya terintegrasi dalam English for Specific Purposes (ESP) seperti tersebut di atas sebagai pendekatan pembelajaran bahasa Inggris dan sebagai salah satu pendekatan pembelajaran terkemuka akademis di perguruan tinggi (Hutchinson and Waters, 1987: 9, Jing Luo dan Mark Garner, 2017: Nur, 2017).

ESP dalam hal ini lebih condong kepada pembelajaran bahasa dalam konteks daripada masalah kaidah bahasa (grammar) dan struktur bahasa. Oleh karena itu, konteks autentik dan penggunaan bahasa dalam situasi yang khas dapat membangkitkan semangat pembelajaran ESP (Vaičiūnienè, 2009; Fiorito, 2005, dalam Vaičiūnienė dan Užpalienè, 2010). Pemaknaan dalam konteks pada perspektif tersebut adalah berorientasi pada isi (content) materi pembelajaran bahasa Inggris menurut disiplin ilmu tertentu. Demikian juga halnya dengan pemaknaan situasi yang khas berorientasi pada isi materi pembelajaran bahasa Inggris sesuai dengan bidang ilmu sebagai motivasi bagi pembelajar/mahasiswa dibandingkan dengan isi mata kuliah 
bahasa Inggris yang isinya masalah kaidah bahasa Inggris yang tidak terkait dengan bidang keilmuan mereka.

Penerapan ESP di Jepang misalnya, sebagaimana diakui oleh Evans dan Squires (2006:17)" ...kami melihat bahwa ESP akan menjadi acuan tanpa kecuali, termasuk berbagai universitas di Jepang, menggantikan kurikulum bahasa Inggris umum". Gagasan yang sama juga oleh Hewings: (A history of ESP through English for Specific Purposes), dalam world.info (2010) menyatakan "Perkembangan pemakaian bahasa Inggris sebagai alat komunikasi dalam berinteraksi antara yang bukan penutur bahasa Inggris, tampaknya mempunyai dampak pada semacam program ESP yang kami siapkan, dan tipe penelitian yang diperlukan untuk mendukung program tersebut. Dengan demikian, tidak ada keraguan untuk mencermati perkembangan ini, baik untuk jurnal ESP mendatang maupun bahasa Inggris dunia tujuan khusus" (halaman 12). Hal senada diperkuat oleh pernyataan Hutchinson \& Waters (1987) dalam Mo (2005:1) "Ekspansi permintaan terhadap bahasa Inggris untuk kebutuhan tertentu dan perkembangan linguistik serta psikologi pendidikan, telah menimbulkan peningkatan pertumbuhan ESP”. pemikiran yang sama juga seperti yang digagas oleh pemerintah Albania menyangkut ESP sebagaimana yang dikutip dari Beshaj (2015:11) tentang pentingnya ESP: "it is obvious that knowing English and using English for specific purposes is a challenge. It can be said that ESP is acquiring a special status in Albania”. Bahkan, di perguruan tinggi Prancis terkait dengan tingkat perkembangan pembelajaran ESP yang ditandai dengan pembentukan kelompok peneliti ESP seperti yang nyatakan oleh Sarré and Whyte (2016:7) "the higher education ESP research group GERAS (Groupe d'Étude et de Recherche en Anglais de Spécialité)", sehingga ia menyebut ESP research and teaching are often qualified as "innovative", yakni tingkat pertumbuhan ESP yang sangat inovatif.

Karena mata kuliah bahasa Inggris tergolong kurikulum institusional yang materi atau isinya diatur dan ditentukan atas kewenangan institusi menurut kepmendiknas di atas, ditengarai adanya keberagaman tataran isi dan orientasinya, yang tidak selalu mencerminkan ciri khas bidang atau 
program studi. Hal ini dapat diidentifikasi dan diinvestigasi selanjutnya melalui kurikulum atau silabus prodi pada PT umum.

\section{2. Kerangka Teori}

Bahasa Inggris untuk sains dan teknologi (EST) sebagai bagian dari ESP dalam penelitian ini, mengikuti Swales (1985) dalam Hutchinson dan Waters, (2006:9) yang mengilustrasikan pengembangan ESP dengan menyatakan:

'With one or two exceptions...English for Science and Technology has always set and continous to set the trend in theoretical discussion, in ways of analyzing language, and in the variety of actual teaching materials"

Sudut pandang ini akan dijadikan acuan untuk selanjutnya mengkaji ESP pada PT umum. Hal ini penting untuk ditekankan karena tujuan nasional dan institusi pendidikan (Čižinauskienè dan Poškienè, 2001: 1) adalah mengembangkan sumber daya manusia yang berminat belajar bahasa Inggris. Selanjutnya mereka diharapkan tahu bahwa pengetahuan tentang pembelajaran bahasa Inggris mempunyai tujuan khusus untuk :

"Para pembelajar/mahasiswa yang nampaknya memiliki minat dan kebutuhan yang berbeda, yang berpengaruh secara mendasar terhadap motivasi untuk belajar dan berikutnya pada keefektifan belajar mereka" (Hutchinson dan Waters, 1992, dalam Čižinauskienè dan Poškienè, 2001:1) .

Selanjutnya, Swales (1985) dalam Čižinauskienė dan Poškienė (2001:1) menyatakan area bahasa Inggris untuk sains dan teknologi (EST)

"Diketahui telah berkembang secara khusus dengan cepat. Yakni, Bahasa Inggris untuk Sains dan Teknologi yang selalu dibenahi dan berlanjut menjadi tren dalam pembahasan teoritis, dengan cara menganalisis bahasanya dan keberagaman materi pengajarannya secara aktual"

Seiring dengan pembenahan tersebut, pembelajaran ESP dapat dilihat dari orientasi pada beberapa tujuan yang berlainan, seperti; English for Academic Purposes (EAP), English for Occupational Purposes (EOP), English for Bussines and Economics (EBE), English for Social Sciences (ESS), dan lain-lain, di samping EST tersebut di atas, (lihat Trimble 1985, Hutchinson and Waters 1987, Robinson 1991, Holliday 1995 dalam Chen, 2006: 2). Keberagaman tersebut dapat mengacu kepada apa yang disebut dengan "ESPTree", yakni semacam pemetaan pembelajaran komunikasi melalui sarana bahasa Inggris untuk kebutuhan tertentu dalam berbagai bidang keilmuan. 
Misalnya yang relevan dengan sains dan teknologi atau teknologi informasi, pembelajaran EST yang paling memungkinkan dan relevan dengan genre tersebut, seperti model berikut:

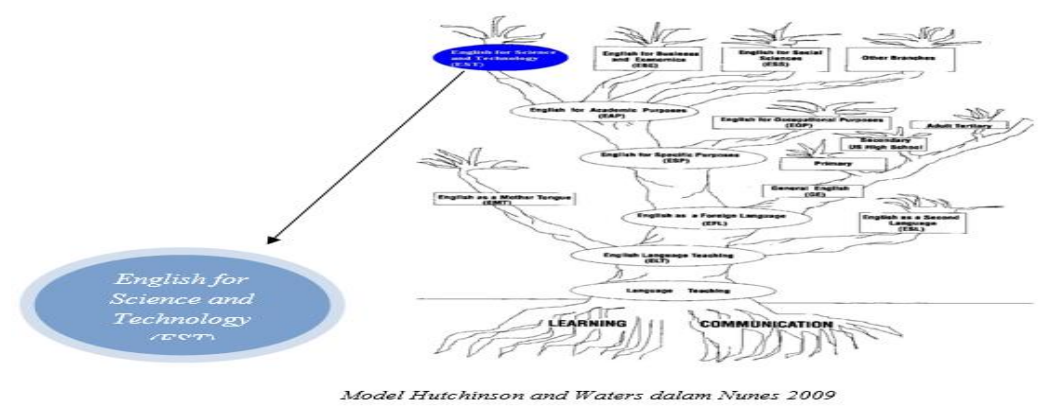

Dalam proses pembelajarannya,

modifikasi definisi terhadap variabel ESP memiliki sejumlah karakteristik, di antaranya seperti yang disebutkan Strevens (1988), Gatehouse (2001) karateristik ESP:

dalam Chen (2006: 2) sebagai berikut:

- dirancang untuk menyesuaikan kebutuhan khusus pembelajar/mahasiswa;

- terkait dengan isi (misalnya; sejumlah tema dan topik-topik) untuk disiplin ilmu tertentu, pekerjaan dan aktivitas).

Mengacu pada sumber yang sama, selanjutnya Dudley-Evans dan St. John (1998, pada halaman 4 sampai 5, seperti yang disebutkan dalam Gatehouse, 2001), menawarkan

- ESP bisa dikaitkan dengan atau dirancang untuk disiplin tertentu;

- ESP dapat digunakan, dalam situasi pengajaran khusus, metodologi yang membedakan dengan pembelajaran bahasa Inggris umum;

- ESP cenderung dirancang untuk pembelajar dewasa, baik institusi selevel perguruan tinggi atau dalam situasi tugas profesional. Namun, dapat juga bagi pembelajar setingkat sekolah menengah.

Berkenaan dengan sejumlah karakteristik ESP yang diuraikan di atas, berikut dapat disampaikan pendekatan pembelajaran CBI, yaitu 
suatu pendekatan pembelajaran bahasa yang mengintegrasikan penyajian sejumlah topik atau tugas kelas mata kuliah dalam konteks pengajaran bahasa kedua atau selaku bahasa asing" (Crandall \& Tucker, 1990: 187). Menurut Krashen dan Biber, satu cara untuk memberikan pemahaman input secara langsung adalah dengan pengajaran isi, menggunakan sejumlah strategi dan teknik dalam bahasa Inggis yang memberikan pemahaman isi bagi pembelajar bahasa kedua. Penelitian ini menegaskan bahwa pembelajar di kelas dengan sejumlah strategi dan teknik tersebut digunakan untuk memperoleh tambahan pengetahuan bahasa Inggris dan beberapa masalah dalam mempelajari isinya (Naqvi dan Mathew, 2010:1). Hal ini lebih detail dapat disampaikan dalam batasan dan hal-hal yang terkait dengan pendekatan ini.

\subsection{Pengertian CBI}

Ada beberapa definisi CBI dengan penekanan yang berbeda dalam konteks pembelajaran bahasa. Brinton, Snow, \& Wessche (1989: 2) mendefinisikan $\mathrm{CBI}$ sebagai "the concurrent teaching of academic subject matter and second language skills" dan Richards \& Schmidt (2002: 115) mendefinisikannya sebagai “ $a$ programme in English as a second language in which the focus is on teaching students the skills they will need in regular classrooms, i.e. for learning in the content areas such as maths, geography, or biology". Kedua definisi ini mengemukakan CBI dalam konteks pembelajaran bahasa kedua dalam bidang tertentu. Pengertian CBI yang lain dikemukakan oleh Crandall \& Tucker (1990: 187), yang mendefinisikannya sebagai "an approach to language instruction that integrates the presentation of topics or tasks from subject matter classes (e.g., math, social studies) within the context of teaching a second or foreign language" dan Wesche \& Skehan (2002: 220), yang mendefinisikannya sebagai "the integration of school or academic content with language teaching objectives". Kedua definisi ini menunjukkan bahwa CBI dapat diterapkan, baik pada konteks pembelajaran bahasa kedua maupun pembelajaran bahasa asing. Keempat definisi tersebut mewakili pengertian CBI secara umum, yaitu CBI sebagai pendekatan dalam pembelajaran bahasa Inggris yang menyatukan isi mata pelajaran atau kuliah dengan penggunaan bahasa agar para mahasiswa kelak dapat 
mengomunikasikan gagasan-gagasan yang relevan dengan mata pelajaran atau kuliah tertentu. Dengan demikian, pembelajaran bahasa Inggris dapat menggunakan, misalnya, bahan-bahan MIPA atau yang berbasiskan teknologi.

CBI adalah salah satu nama yang muncul dalam perkembangan ESP. Salah satu manfaat dari CBI adalah bahwa penggunaan materi mata kuliah/pelajaran tertentu sebagai bahan pembelajaran bahasa dapat memaksimalkan pengeksposan mahasiswa/siswa pada bahasa yang dipelajarinya. Pengeksposan ini bersifat kontekstual karena sesuai dengan kebutuhan mahasiswa/siswa.

Pembelajaran melalui CBI yang berhasil dapat menjadikan mahasiswa/siswa menguasai bahasa maupun isi mata kuliah/pelajaran melalui proses timbal balik. Dalam konteks pembelajaran bahasa Inggris sebagai bahasa asing, melalui CBI, mahasiswa/siswa perlu terlibat dalam beragam kegiatan agar dapat menguasai bahasa sasaran dan isi mata kuliah/pelajaran. Nunan (2004: 132) menyebutkan beberapa manfaat dari CBI. Manfaat-manfaat tersebut antara lain "an organic, analytical approach to language development" dan " $a$ framework within which learners can have sustained engagement on both content mastery and second language acquisition". Meskipun Nunan menyebutkan manfaat tersebut dalam konteks bahasa kedua, manfaat dalam konteks bahasa asing tidak jauh berbeda. Selanjutnya, Nunan (2004: 132), dengan mengutip Brinton (2003), menyebutkan lima prinsip dalam CBI:

1. Kegiatan pembelajaran didasarkan pada isi, bukan pada aspek kebahasaan.

2. Keterampilan hendaknya terintegrasi.

3. Mahasiswa/siswa hendaknya secara aktif terlibat dalam semua tahap proses pembelajaran.

4. Isi hendaknya dipilih berdasarkan relevansinya dengan kebutuhan mahasiswa/siswa yang sejalan dengan tujuan akademik.

5. Bahan-bahan dan tugas-tugas hendaknya autentik.

Dengan demikian, melalui $\mathrm{CBI}$, mahasiswa/siswa mempelajari bahasa Inggris melalui topik-topik dalam mata pelajaran/kuliah, seperti matematika, biologi, fisika, dan kimia. Dengan pengantar bahasa inggris, mereka sekaligus mempelajari materi tersebut. Melalui cara ini, mahasiswa/siswa dapat diharapkan mengomunikasikan, baik secara lisan maupun tertulis, gagasan-gagasan yang relevan dengan materi tersebut karena pembelajaran bahasa Inggris menggunakan bahan darinya. Penerapan CBI dalam praktik 
dapat ditempuh dengan berbagai cara. Crandall dkk. (1987) mengemukakan dua model pembelajaran bahasa Inggris melalui CBI. Model yang pertama adalah content-driven (berdasarkan isi) dan yang kedua adalah language-driven (berdasarkan bahasa). Ciri-ciri dari kedua model tersebut, seperti yang diadaptasi dari Suharso (2011: 5) sebagai

Ciri-ciri CBI berdasarkan isi dan CBI berdasarkan bahasa

\begin{tabular}{|c|c|}
\hline Berdasarkan Isi & Berdasarkan Bahasa \\
\hline Isi diajarkan dengan Bahasa Inggris & $\begin{array}{c}\text { Isi digunakan untuk mempelajari Bahasa } \\
\text { Inggris }\end{array}$ \\
\hline Pembelajaran isi menjadi prioritas & Pembelajaran bahasa menjadi prioritas \\
\hline Pembelajaran isi bersifat sekunder & Pembelajaran bahasa bersifat sekunder \\
\hline $\begin{array}{c}\text { Guru/dosen perlu memilih isi yang akan } \\
\text { diintegrasikan }\end{array}$ & $\begin{array}{c}\text { Guru /dosen perlu memilih tujuan } \\
\text { pembelajaran bahasa }\end{array}$ \\
\hline $\begin{array}{c}\text { Tujuan pembelajaran isi ditentukan oleh } \\
\text { kompetensi dalam mata pelajaran/kuliah }\end{array}$ & $\begin{array}{c}\text { Tujuan pembelajaran bahasa ditentukan oleh } \\
\text { kompetensi dalam kebahasaan }\end{array}$ \\
\hline $\begin{array}{c}\text { Evaluasi siswa/mhs didasarkan pada penguasan } \\
\text { isi }\end{array}$ & $\begin{array}{c}\text { Evaluasi siswa/mhs didasarkan pada } \\
\text { kemahiran/keterampilan berbahasa }\end{array}$ \\
\hline
\end{tabular}

Pembagian di atas tidak bersifat pilah. Artinya, pengajar dapat secara luwes menerapkan CBI sesuai dengan keadaan pembelajar; apakah dia cenderung menerapkan CBI yang berdasarkan isi atau yang berdasarkan bahasa. Dalam CBI yang berdasarkan isi, pembelajaran terhadap isi materi kuliah lebih penting daripada pembelajaran bahasa. Penguasaan isi materi menjadi tujuan utama pembelajaran. Dalam CBI yang berdasarkan bahasa, isi materi digunakan sebagai sarana untuk memperkaya tujuan pembelajaran bahasa. Pembelajaran isi materi kuliah tidak menjadi tujuan utama. Kedua model yang diuraikan di atas mirip dengan bentuk CBI yang dikemukakan oleh Wesche \& Skehan (2002), yaitu bentuk lemah (weak form) dan bentuk kuat (strong form). Bentuk lemah adalah CBI yang bertujuan mengembangkan kemahiran komunikatif pembelajar melalui silabus kebahasaan yang disusun berdasarkan isi materi kuliah tertentu. Silabus disusun berdasarkan keterampilan berbahasa dan diorganisasikan dengan mengacu pada teks-teks yang relevan dengan materi, yang berfungsi sebagai program pendukung penguasaan keterampilan berbahasa.

\section{Metode Penelitian}

Metode penelitian ini adalah bersifat deskriptif kualitatif terhadap data penelitian dalam bentuk dokumen silabus Perguruan Tinggi (PT) secara sampling yang ditetapkan secara acak dengan representasi program studi 
(prodi) berjumlah delapan institusi.

Metode dalam penelitian mengacu pada Zaim M. (2014:13) yang menyatakan bahwa metode kualitatif diskriptif menyajikan secara langsung data kebahasaan yang didapat di lapangan sesuai dengan penggunaannya. Selanjutnya, teknis pengumpulan data adalah melalui observasi langsung terhadap PT untuk data primer dengan representasi dua prodi, dan pengumpulan data prodi dari PT melalui survei internet untuk data sekunder sejumlah enam prodi.
Dalam hal ini, tidak dibedakan antara prodi PT berdasarkan status negeri atau swasta, jenis pendidikan, dan/atau secara geografis. Sebaliknya, yang menjadi fokus penelitian ini adalah investigasi materi dan orientasi mata kuliah bahasa Inggris dalam konteks bidang atau program studi pada PT menurut ciri khas yang bersangkutan.

\section{Pembahasan}

\subsection{Deskripsi Data}

\subsubsection{Data PT dan Tema Materi}

\begin{tabular}{|c|c|c|c|c|}
\hline No. & $\underset{\text { PT }}{\text { NAMA }}$ & $\begin{array}{c}\text { CIRI KHAS } \\
\text { PROG. STUDI/PT }\end{array}$ & $\begin{array}{c}\text { TEMLA MATERI } \\
\text { TAHUN AKADEMIK }\end{array}$ & KETERANGAN \\
\hline 1. & PT1 & $\begin{array}{l}\text { Prog.Studi Telonik } \\
\text { Informatika }\end{array}$ & $\begin{array}{l}\text { English Grammar \& } \\
\text { General Reading Skills } \\
\text { TA 2009/2010 }\end{array}$ & 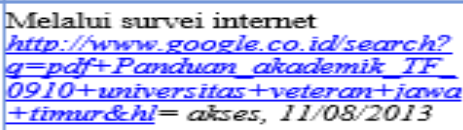 \\
\hline 2. & PT2 & $\begin{array}{l}\text { Prog. Studi } \\
\text { Pertanian }\end{array}$ & $\begin{array}{l}\text { General Reading Skills } \\
\text { TA. 2009/2010 }\end{array}$ & $\begin{array}{l}\text { Melalui survei langsung } \\
21 / 09 / 2013\end{array}$ \\
\hline 3. & PT 3 & $\begin{array}{l}\text { Prog. Studi Ilmu } \\
\text { Pertanian }\end{array}$ & $\begin{array}{l}\text { English Grammar } \\
\text { TA 2009/2010 }\end{array}$ & $\begin{array}{l}\text { Melalui survei langsung } \\
19 / 10 / 2013\end{array}$ \\
\hline 4. & PT 4 & $\begin{array}{l}\text { Prog. Studi Ilmu } \\
\text { Komunikasi }\end{array}$ & $\begin{array}{l}\text { English Grammar } \\
2010 / 2011\end{array}$ & $\begin{array}{l}\text { Melalui survei internet } \\
\text { http://sap.tarumanagara ax.idlen } \\
\text { fikom } / 40 \text {-sap-bahasa- } \\
\text { inggris.html akses } 04 / 11 / 2013\end{array}$ \\
\hline 5. & PT 5 & $\begin{array}{l}\text { Prog. Studi Teknik } \\
\text { Informatilca. }\end{array}$ & $\begin{array}{l}\text { Kombinasi: Englïsh for } \\
\text { Engineering dan English } \\
\text { for General Skills } \\
\text { TA 2009/2010 }\end{array}$ & 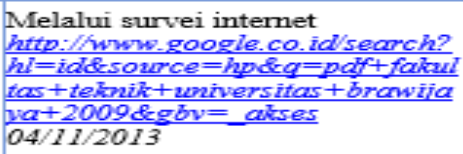 \\
\hline 6. & PT 6 & $\begin{array}{l}\text { Prog. Studi Teknik } \\
\text { Informatika }\end{array}$ & $\begin{array}{l}\text { General Reading Skills } \\
\text { TA 2013/2014 }\end{array}$ & 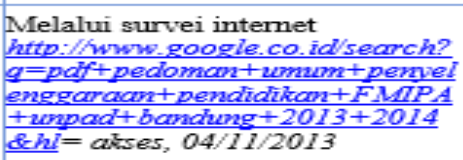 \\
\hline 7. & PT7 & $\begin{array}{l}\text { Prog. Studi Tata } \\
\text { Boga }\end{array}$ & $\begin{array}{l}\text { Kombinasi multidisiplinn } \\
\text { Nixture English- } \\
\text { TA } 2007 / 2008\end{array}$ & 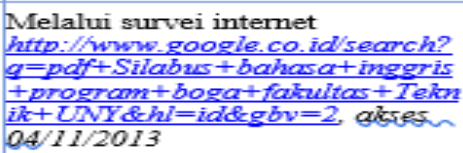 \\
\hline 8. & PTs & $\begin{array}{l}\text { Prog. Studi Olah } \\
\text { Raga Kesehatan }\end{array}$ & $\begin{array}{l}\text { Kombinasi: Four Skills } \\
\text { Development dan } \\
\text { English for Sport and } \\
\text { Health } \\
\text { TA. 2010/2011 }\end{array}$ & 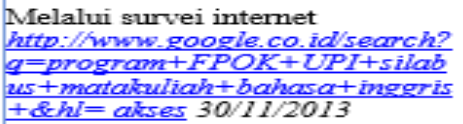 \\
\hline
\end{tabular}


Mengacu pada tabel data PT dan tema materi, ditetapkan 8 (delapan) program studi dari beberapa PT yang dijadikan sebagai sumber data. Selanjutnya, data tersebut menjadi ukuran untuk mengidentifikasi konsistensi antara program studi (major) mahasiswa pada suatu PT menurut ciri khas yang bersangkutan, dengan materi/isi mata kuliah bahasa Inggris. Data yang diperoleh tersebut, dapat diasumsikan mewakili data sejenis secara umum sebagai bagian dari langkah triangulasi, yakni tidak hanya menggunakan satu sumber data (Budiwicaksono, 2013) maupun menjadi bukti atau data yang berbeda untuk memperoleh kebenaran handal (Rahardjo, 2010). Dengan demikian, sejumlah data yang ada dalam tabel 1 dapat menjadi acuan peneliti untuk menginvestigasi menurut permasalahan yang dikemukakan di atas.

Selanjutnya, dari segi klasifikasi, data ini digolongkan menjadi data primer dan data sekunder. Data primer adalah data yang diperoleh langsung dari pihak program studi pada PT terkait sesuai dengan letak geografis atau lokasi, sedangkan data sekunder, adalah data yang diperoleh melalui penelusuran internet dengan memanfaatkan layanan mesin pencari atau broser yang ada. Kedua jenis data ini, baik yang tergolong data primer maupun data sekunder, dimasukkan dalam tabel berdasarkan waktu survei, seperti yang terdapat pada tabel kolom keterangan.

\subsubsection{Data Primer}

Data yang tergolong data primer dengan mengacu pada tabel di atas, sebagaimana yang diperoleh pada PT2 dan PT3, pada kolom ciri khas program studi dan tema materi merupakan bagian yang menjadi fokus pada pembahasan ini, yakni konsistensi antara ciri khas program studi pada suatu PT dan tema materi yang menjadi isi mata kuliah bahasa Inggris. Data pada tabel 2 yang tergolong data sekunder ini, memliki lingkup bidang keilmuan yang sama yakni pertanian, namun, memiliki substansi tema materi yang berbeda terhadap isi mata kuliah bahasa Inggris bila diukur berdasarkan referensi, yakni PT2 berkaitan dengan English for General Purposes (EGP), sedangkan PT3 berkaitan dengan English Grammar (EG). EGP secara umum berorientasi pada pemahaman informasi atau pesan yang terkandung pada teks tertulis. Indikasi hal ini dengan mengacu pada referensi yang tertera pada silabus yang bersangkutan, seperti; reading developing skills. 
Kemudian, EG berorientasi pada pemahaman kaidah kebahasaan (bahasa Inggris). Indikasi hal ini mengacu pada referensi yang tertera pada silabus yang bersangkutan, seperti; Practical English Grammar, Understanding and Using English Grammar in, English structure in Context.

\subsubsection{Data Sekunder}

Data sekunder dengan mengacu pada tabel di atas, sebagaimana yang diperoleh pada PT1, PT4, PT5, PT6, PT7, dan PT8, antara kolom ciri khas program studi dengan tema materi bahasa Inggris, secara substansial dapat dikelompokkan menjadi tiga (3) kategori tema materi. Setiap kategori tema materi tersebut, yakni; English for General Purposes (EGP), English Grammar (EG), dan kombinasi antara English for Specific Purposes (ESP) dengan English for General Purposes (EGP) diklasifikasi menurut referensi yang tercantum pada setiap silabus PT yang bersangkutan.

\subsection{Diskripsi Data Menurut Tema Materi.}

Data menurut tema materi dengan mengacu pada tabel 1 yang tergolong data primer dan tabel 2 yang tergolong data sekunder dapat direpresentasikan sebagai berikut.

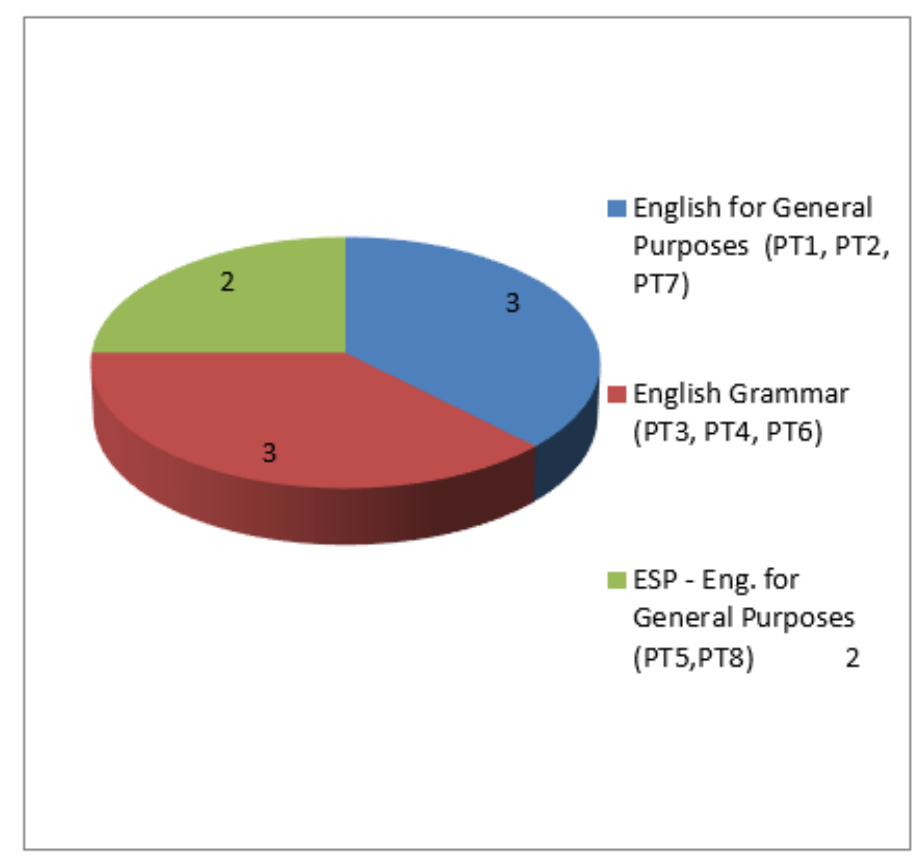

Gamhar Klasifikasi Toma Mntori 


\subsubsection{Diskripsi Tema Materi EGP}

Tema materi pada silabus yang dikatagorikan EGP pada PT1, PT2, dan PT7, di samping mengacu pada referensi yang tercantum pada setiap silabus, juga mengacu pada indikator kompetensi silabus tersebut. Misalnya, PT1 yang membidangi teknik informatika pada diskripsi silabusnya menekankan pada penguasaan wacana yang berkenaan dengan sains dan teknologi, dan dikombinasi dengan penguasaan pengetahuan gramatika bahasa Inggris secara umum. Selanjutnya, PT2 yang membidangi masalah pertanian, merujuk pada referensi Developing Skills untuk pengembangan pemahaman bacaan dengan beragam tema. PT7 program studi Tata Boga sebagaimana yang tercantum pada silabusnya, menekankan kemampuan mahasiswa pada penguasaan empat ketrampilan berbahasa untuk materi-materi yang bertemakan keilmuan eksak. Dengan demikian, isi/materi mata kuliah bahasa Inggris pada PT umum terkait direkomendasikan untuk menyusun silabus sebagai iktisar materi/isi mata kuliah, sehingga konsisten dan mencerminkan bidang atau program studi PT yang bersangkutan.

\subsection{Diskripsi Tema Materi $E G$}

Tema materi pada silabus yang dikatagorikan English Grammar pada PT3, PT4, dan PT6, di samping mengacu pda referensi yang tercantum pada setiap silabus, juga mengacu pada indikator kompetensi silabus tersebut. Misalnya, PT3 yang membidangi ilmu pertanian, namun menekankan mahasiswa pada penguasaan struktur bahasa Inggris dengan merujuk pada materi-materi Understanding and Using English Grammar, English Sentence Structure, Practical English Grammar. Kemudian, PT4 yang membidangi ilmu komunikasi, menekankan mahasiswa pada penguasaan tensis, pola atau struktur kalimat-kalimat bahasa Inggris, dan PT6 yang membidangi masalah teknik informatika, menekankan pada mahasiswa untuk menguasai Integrated Practice in English, Course in English Grammar. Fenomena tersebut, bila mengacu pada prinsip pembelajaran ESP yang berbasiskan pada isi, maka tidak konsisten dan tidak spesifik antara bidang keilmuan mahasiswa dengan materi yang disajikan pada mata kuliah MPK, yang menekankan pada optimalisasi pengesposan materi bidang keilmuan mahasiswa melalui bahasa (dalam hal ini bahasa Inggris) yang mereka pelajari. Dengan demikian, isi/materi mata kuliah bahasa Inggris pada PT umum terkait direkomendasikan untuk menyusun silabus sebagai iktisar materi/isi mata kuliah, sehingga konsisten dan mencerminkan bidang atau program studi PT yang bersangkutan. 


\subsubsection{Diskripsi Tema Materi ESP dan EGP}

Tema materi pada silabus yang dikatagorikan kombinasi ESP dan EGP pada PT5 dan PT8 dengan mengacu pada silabus yang tercantum pada setiap silabus yang bersangkutan. Pada PT5 yang membidangi teknik informatika, memang menekankan pembelajaran bahasa Inggris tujuan khusus (English for Science and Technology) kepada mahasiswa, namun masih dikombinasikan dengan pola-pola pembelajaran general, seperti; penggunaan istilah-istilah scanning, skimming, making inference, main ideas dan sejenisnya dalam konteks pemahaman teks yang secara terpisah dari prinsip pembelajaran bahasa Inggris tujuan khusus (ESP). kemudian, pada PT8 yang membidangi pendidikan olahraga dan kesehatan, memang menekankan pemahaman kepada mahasiswa secara khusus pada pembelajaran bahasa Inggris tujuan khusus, yakni English for Sport and Recreation, namun masih dikombinasi dengan materimateri dalam konteks The teaching of Structural Words and Sentence Patterns, Expanding Reading Skills, University Grammar of English. Hal ini, menggambarkan ketidakkonsistenan antara bidang keilmuan mayor mahasiswa dan prinsip pembelajaran ESP dengan apa yang ditekuni mahasiswa. Dengan demikian, isi/materi mata kuliah bahasa Inggris pada
PT umum terkait, direkomendasikan untuk menyusun silabus sebagai iktisar materi/isi mata kuliah sehingga konsisten dan mencerminkan bidang atau program studi PT yang bersangkutan.

\section{Penutup}

Pembelajaran bahasa Inggris sebagai Matakuliah Pengembangan Kepribadian (MPK) dengan mengacu pada hasil investigasi data menunjukkan ketidakonsistenan antara bidang atau program studi PT terkait dengan isi/materi mata kuliah bahasa Inggris. Hal ini, bila diukur dari diskripsi kompetensi dan referensi yang diacu oleh silabus tersebut, sebagaimana klasifikasi tema materi pada gambar 5.3 tentang data berdasarkan tema materi. Materi pembelajaran bahasa Inggris dengan mengacu pada silabus dari program studi pada data dapat dikelompokkan ke dalam tiga katagori, yakni (1) English for General Purposes (data: PT-1, PT-2, dan PT-7); (2) English Grammar (data: PT-3, PT-4, dan PT-6); dan (3) ESP dan English for General (data PT-5, dan PT-8). Dengan demikian, tidak terdapat program studi dari sejumlah PT tersebut yang menerapkan pembelajaran ESP dengan pendekatan CBT pada mata kuliah bahasa Inggris yang mencerminkan ciri khas bidang keilmuannya. Dengan menyadari urgensi penerapan ESP yang mencakup English for Academic Purposes (EAP) dan 
pembelajaran bahasa Inggris yang berorientasi pada kepentingan profesi atau pekerjaan yang dikenal dengan English for Occupation (EOP), ke depan diharapkan hasil kajian ini dapat melengkapi gagasan dalam kajian-kajian sebelumnya dalam rangka kajian mata kuliah bahasa Inggris

\section{Daftar Pustaka}

Alemi, Minoo dan Ebadi, Saman. (2010). The Effects of Pre-reading Activities on ESP Reading Comprehension. Sharif University of Technology, Tehran, Iran: ACADEMY PUBLISHER. Journal of Language Teaching and Research, Vol. 1, No. 5, pp. 569--577.

Braxton, S. (2003). General Instructional Design Phases. Retrieved on November 24th, 2006 from http://www.futureu.com/publications/ braxton/general_phases.html

Beshaj, Lediana. (2015). The Growing Importance of English for Specific Purposes (ESP) in Albanian Higher Education. International Journal on Studies in English Language and Literature (LJSELL) Volume 3, Issue 6, June 2015, PP 10-13 ISSN 23473126 (Print) \& ISSN 2347-3134.

Brinton, D.M., Snow, M.A., \& Wesche, M.B. (1989). Content-based Second Language Instruction. Boston: Heinle $\&$ Heinle.

Brinton, Snow, \& Wesche. (1989). wikipedia ${ }^{\circledR}$ of the WikipediaFoundation, Inc., a nonprofit organization. Akses 22/02/2012. secara komprehensif di PT (non-English majors) yang mengintegrasikan kepentingan spesifikasi bidang keilmuan dan bahasa Inggris secara akademik dan profesional.

Čižinauskienė dan Poškienè. (2001). English for Science and Technology (EST) at the Level of Master Studies. KALBŲ STUDIJOS .Journal. Studies About Languages. No.1. ISSN 1648-2824.

Chamot, Anna Uhl. (2004). Issues in Language Learning Strategy Research and Teaching. Electronic Journal of Foreign Language Teaching. National University of Singapore. (c) Centre for Language Studies. Vol. 1, No. 1, pp. 14--26.

Chen, Yong. (2006). From Common Core to Specific. British Virgin Island. The Asian ESP Journal. Vol. 1(3). p.2.

Crandall, J. dkk. (987). Integrating language and content instruction for language minority students. Teacher Resource Guide Series, Number 4 September 1987. http://www.ncela.gwu.edu/pubs/classi cs/trg/04integrating.htm.

Crandall, J. dan Tucker, G. R. (1990). Content-based instruction in second and foreign languages. In A. Padilla, H. H. Fairchild and C. Valadez (eds.) Foreign Language Education: Issues and Strategies. Newbury Park, CA: Sage. 
Direktorat Akademik-Direktorat jenderal Pendidikan Tinggi. (2008). Buku Panduan Pengembangan Kurikulum Berbasis Kompetensi Pendidikan Tinggi. Sebuah Alternatif Penyusunan Kurikulum. Jakarta: Depdiknas. Hlm.5.

Dudley-Evans T. (2001). English for Specific Purposes, in Carter R. And Nunan D. (Eds). The Cambridge Guide to Teaching English to Speakers of other Languages. Cambridge: Cambridge University Press.

Dudley-Evans T. and St. John M. J. (1998). Developments in English for specific Purposes. Cambridge: Cambridge University Press.

Evans, Heidi dan Squres, Todd. (2006). Good Practices for ESP Programs in Japanese Post-secondary Institutions. The Japan Association for Language Teaching. Volume 30, Number 9. hlm. 17.

Fadjar, A. Malik. (2002). Menteri Pendidikan Nasiona. Keputusan Menteri Pendidikan Nasional Nomor: 045/U/2002. Tentang Kurikulum Inti Pendidikan Tinggi. Jakarta.

Gatehouse, K. (2001). Key issues in English for Specific Purposes: (ESP) Curriculum development. TESL Journal Vol. VII, No.10, October 2001, http://www.iteslj.org/Articles/Gateho use-ESP.html, Retrieved August, 2006.

Hewings. A history of ESP through English for Specific Purposes, dalam http://www.espworld.info/Articles_3/Hewings_paper .htm/, diakses 02/09/2010.
Hutchinson, T, \& Waters, W. (1987). English for Specific Purposes-A learning-centered approach. Cambridge: Cambridge: Cambridge University Press.

Hutchinson, Tom, dan Waters Alan. (2006). English for Specific Purposes. $22^{\text {nd }}$ printing. United Kingdom. Cambridge University Press.

Johnson, K. \& Johnson, H. (1999). Encyclopedic Dictionary of Applied Linguistics. Oxford: Blackwell Publishers.

Kavaliauskienè, Galina. (2004). Research into the Integration of Content-Based Instruction into the ESP Classroom. Journal of Language and Learning. Vol.2, No.2. ISSN 1740-4983. Law University of Lithuania, Vilnius, Lithuania.

Kusni. (2007). Reformulasi Perancangan Program ESP di Perguruan Tinggi. Universitas Negeri Padang. Linguistik Indonesia, Tahun ke 25, No. 1.

Luo, Jing dan Mark Garner. (2017).The Challenges and Opportunities for EnglishTeachers in Teaching ESP in China. Journal of Language Teaching and Research, (8),1, pp.81--85

Marìa, Dueñas. (2004). The Whats, Whys, Hows and Whos of Content-Based Instruction in Second/Foreign Language Education. Servicio de Publicaciones. Universidad de Murcia. All rights reserved. IJES, vol. 4 (1), 2004, pp. 73--96.

Marina, Valerija dan Marmienè, Auksè. (2006). Text-Based Language Teaching and the Analysis of Tasks Presented in English Course Books 
for Students of Information Iechnology and Computing. Santalka. Filologija. Edukologija. 2006, T. 14, Nr. 2. ISSN $1822-430 X$ print $1822-$ 4318 online.

Miarso, Yusuf Hadi. (1987). Penelitian Instruksional PUA Survey Model Pengembangan Instruksional. Jakarta: Depdikbud: Dirjen Dikti.

Mo, Huanran. (2005). A Brief Review of English for Academic Purposes (EAP). Zhuhai Campus, Zunyi Medical College. US-China Foreign Language, ISSN1539-8080, USA. Volume 3, No.7 (Serial No.22).

Muhaimin, Yahya, A. (2000). Menteri Pendidikan Nasional. Keputusan Mendiknas RI., Nomor: 232/U/2000. Tentang Pedoman Penyusunan Kurikulum Pendidikan Tinggi dan Penilaian Hasil Belajar Mahasiswa. Jakarta.

Naqvi dan Mathew. (2010). ESP Course for IT Students at the Middle East College of Information Technology, Sultanate of Oman: Design and Application Language Education in Asia, 2010, vol. 1(1), 242--257.

Nunan, D. (2004). Task-based Language Teaching. United Kingdom Cambridge: Cambridge University Press.

Nur, Muhamad. (2017). Pengembangan Kompetensi Komunikatif Mahasiswa Jurusan Teknik Informatika dalam English for Academic Purposes (Studi Kasus di STMIK Bumigora Mataram. Seminar Nasional TIK dan Ilmu Sosial (Socio Tech).STMIK Bumigora Mataram, ISBN: 978-60217488-2-4
Professional Development for Language Teachers Implementing the TexasEssential Knowledge and Skills for Languages Other Than English (TEKS for LOTE). (1997). Project ExCELL Excellence and Challenge: Expectations for Language Learners Southwest Educational Development Laboratory Austin, Texas Texas Education Agency. http://www.google.co.id/search?hl= id \&source $=$ hp \&q $=$ pdf + language+teaching + model $\& g b v=2 \& o$ $\mathrm{q}=\mathrm{pdf}+$ language+teaching+model $\& \mathrm{aq}$ $=\mathrm{f} \& \mathrm{aqi}=\& \mathrm{aql}=\& \mathrm{gs} \_\mathrm{sm}=3 \& \mathrm{gs} \_u p l=1$ 53751246721012589112712710119119101 3591146812-5.11610. diakses 08/03/2012.

Rahardjo, Mudjia. (2010). Triangulasi dalam Penelitian Kualitatif. Artikel http://mudjiarahardjo.uinmalang.ac.id/artikel/270.html,akses 07/12/201.3

Richards, J.C. \& Schmidt, R. (2002). Longman Dictionary of Language Teaching and Applied Linguistics. Harlow: Pearson Education Limited.

Ro'isatin, U. Anis. (2006). Kajian Tentang Pengajaran ESP di Jurusan Rekayasa. Politeknik negeri malang : Jurnal ilmu-ilmu Sosial. Vol.2 No.1ISSN 1858- 2265. hlm. 129-134.

Saricoban. (1999). Http://wiki.answers.com/Q/what_is_r eceptive_-_productive_skill/. Akses 25/02/2012.

Sarré and Whyte. (2016). Research in ESP teaching and learning in French higher education: developing the construct of ESP didactics. Research in ESP teaching and learning in French higher education: developing 
the construct of ESP didactics », ASp [Online], 69 | 2016, Online since 01 March 2017, connection on 05 March 2017.

$U R L$

:http://asp.revues.org/4834 ; DOI : 10.4000/asp.4834.

Savichuk, V.Ya. (2010). Linking Profession and Language: Content-Based Instruction in English for Specific Purposes to Hospitality and Tourism Students. The Department of Foreign Languages for the Students of Natural Sciences and Mathematics.TaBH3. 8.

Silver, R.E. dkk. (2007). Language Education in China, Japan, and Singapore. National Institute of Education- Nanyang Technological University. I Nanyang Walk publisher. Singapore.

Sofyan, Liya, A.S. (2004). Pengajaran ESP pada Tingkat Perguruan Tinggi. Unika Atma Jaya.

Suharso. tanpa Thn. Pembelajaran Bahasa Inggris melalui 'Content-Based Instruction'. Pendidikan Bahasa Inggris FBS Universitas Negeri Yogyakarta.

$h t t p: / / w w w . g o o g l e . c o . i d / s e a r c h ? h l=i d$ $\&$ source $=h p \& q=p d f+P E M B E L A J A R$ AN+BAHASA+INGGRIS+MELAL UI+CONTENT-

BASED+INSTRUCTION+ suharso $+\& \mathrm{gbv}=2 \&$ oq=pdf. akses, juli 2011.

Supriatna, Dadang, dan Mulyadi, Mochamad. (2009). Konsep Dasar desain Pembelajaran. Bahan Ajar untuk Diklat E-Training PPPPTK TK dan PLB. Pusat Pengembagan dan Pemberdayaan Pendidik dan Tenaga kependidikan Taman kanak-kanak dan Pendidikan Luar Biasa.

Wesche, M. B. \& Skehan, P. (2002). Communicative, task-based, and content-based language instruction. In R. B. Kaplan (Ed.) The Oxford Handbook of Applied Linguistics. Oxford: Oxford University Press.

Wicaksono. (2013). Metode Penelitian Triangulasi. Artikel.wordpress. http://budiwicaksono.wordpress.com/ 2013/01/27/metode-penelitiantriangulasi/,akses 07/12/13.

Zaim, M. (2014). Metode Penelitian Bahasa: Pendekatan Struktural. Padang: FBS UNP Pre 